\title{
Time-shrinking, its propagation, and Gestalt principles
}

\author{
TAKAYUKI SASAKI \\ Miyagi Gakuin Women's College, Sendai, Japan \\ DAIGOH SUETOMI and YOSHITAKA NAKAJIMA \\ Kyushu Institute of Design, Fukuoka, Japan \\ and \\ GERT TEN HOOPEN \\ Leiden University, Leiden, The Netherlands
}

\begin{abstract}
When a relatively short empty time interval is preceded by an even shorter one, its duration can be underestimated remarkably. This phenomenon, called time-shrinking, has been investigated with patterns consisting of two time intervals. In five experiments, we investigated whether underestimation of the last interval would occur when it was preceded by two time intervals. Significant underestimations of the last interval occurred in some of those patterns. The influence of the second preceding interval was dominant, but in some patterns, the first preceding interval could shrink the subjective duration of the last time interval directly. The first interval could also affect perception of the duration of the last one indirectly by shrinking the second interval, as a result of which the latter either shrank the last interval more strongly or became too short to shrink it. There were two types of temporal patterns in which the perceived duration of the last interval could not be explained by time-shrinking or its propagation through the pattern. It seemed plausible that auditory Gestalt principles invoked strong figural organizations in these patterns, which rendered the time-shrinking mechanism inoperative.
\end{abstract}

In the present research, we investigated first whether time-shrinking (TS), an illusion of temporal perception in two-interval patterns, also would emerge in three-interval patterns and, second, whether the assimilation process causing this illusion was influenced by Gestalt factors, such as similarity and proximity, in three-interval patterns.

The main part of this article is based upon the master's thesis of D.S., submitted in March 1998 to the Kyushu Institute of Design, Dept. of Acoustic Design, Fukuoka, Japan. D.S. is now in Chiba, Chiba Prefecture, Japan. Parts of this study were presented by him and Y.N. in a joint paper for the Seventh Workshop on Rhythm Perception and Production at the Netherlands Institute of Advanced Studies, Wassenaar, The Netherlands, July 1998. We thank the Ministry of Education, Japan (07459017 in fiscal years 1995-1997, and 10610076 in fiscal years 1998-2000) and the Roland Foundation (in fiscal year 1998) for their financial support to Y.N. We thank the Japanese Society for the Promotion of Science (in 1995) and the Netherlands Organization for Scientific Research (in 1995 and 1999) for their financial support for G.T.H.'s visit to Japan. We thank Miyagi Gakuin Women's College for supporting T.S.'s visit in 1998 to The Netherlands. We dedicate this article to Beppie, who sorted out our messy piles of $\mathrm{A} 4 \mathrm{~s}$ on a regular basis with great enthusiasm but unexpectedly died just before the second draft was finished. Requests for reprints from Asia and the Pacific Rim should be addressed to T. Sasaki, Miyagi Gakuin Women's College, 9-1-1 Sakuragaoka, Aoba-ku, Sendai, 981-8557 Japan (sasaki@mgu. ac.jp); otherwise, they should be addressed to G. ten Hoopen, Leiden University, Faculty of Social \& Behavioral Sciences, Experimental Psychology, P.O. Box 9555, 2300 RB Leiden, The Netherlands (e-mail: tenhoopen@ fsw.leidenuniv. nl). Correspondence can be addressed to either of them.
When two empty time intervals are neighbors to each other and the first one is up to about $100 \mathrm{msec}$ shorter than the second one, the latter duration can be profoundly underestimated. If the difference between the durations of the second and the first intervals exceeds about $100 \mathrm{msec}$, shrinking of the second interval ceases, and the percept of the duration ratio changes. The robustness and the stability of this illusory phenomenon have been shown in various experimental situations and with huge variations of the sound markers that delimited the durations (e.g., Remijn et al., 1999; Suetomi \& Nakajima, 1998; ten Hoopen et al., 1995). In earlier studies from our laboratories, several possible explanations were ruled out, and the Gestalt notion of assimilation was introduced as a first step toward elucidating the mechanism of TS (Nakajima, ten Hoopen, Hilkhuysen, \& Sasaki, 1992; Nakajima, ten Hoopen, \& van der Wilk, 1991; ten Hoopen et al., 1993). Recently, Sasaki, Nakajima, and ten Hoopen (1998) offered clear evidence that the temporal assimilation indeed takes place and that it is basically unilateral-that is, it was shown clearly that the duration of the second empty time interval ( $t 2)$ assimilated to the shorter duration of the first interval $(t 1)$, whereas assimilation in the opposite direction happened only slightly, if ever.

In the present study, our first step was to investigate what would happen to this perceptual mechanism when $t 1$ and $t 2$ were separated by an intervening empty duration. A preliminary study (Sasaki, ten Hoopen, \& Nakajima, 
1992) showed that TS still occurred when $t 1$ and $t 2$ were separated by a silent interval. In that study, there were two values of $t 1: 40$ and $80 \mathrm{msec}$. When $t 1$ was $40 \mathrm{msec}, t 2$ could be $40,60,80$, and $100 \mathrm{msec}$. When $t 1$ was $80 \mathrm{msec}$, $t 2$ could be $80,100,120$, and $140 \mathrm{msec}$. The value of the intervening empty duration ( $I$ ) between $t 1$ and $t 2$ varied between 0 (the neighboring condition as a control), 200, $400,800,1,200$, and 1,600 msec. Typical amounts of underestimation of $t 2$ were found when $I$ was $0 \mathrm{msec}$. For example, in the $/ t 1 / t 2 /$ pattern of $/ 80 / 140 / \mathrm{msec}, t 2$ was underestimated by $43 \mathrm{msec}$. When $t 1$ and $t 2$ were separated by an $I$ of $200 \mathrm{msec}$ or of $400 \mathrm{msec}$, significant underestimations still occurred. The amounts were 27 and $23 \mathrm{msec}$, respectively. Because we knew from our previous studies that $t 2$ could not be shrunk by longer preceding durations, we concluded that $t 2$ had assimilated to $t 1$.

The general trend in Sasaki et al. (1992) was that underestimations were maximum when $I$ was $0 \mathrm{msec}$ and decreased approximately linearly when $I$ increased from 0 to $400 \mathrm{msec}$. The amount of underestimation remained at a plateau of about 5-15 msec between $I=400 \mathrm{msec}$ and $I=1,600 \mathrm{msec}$. The authors suggested that two mechanisms of time perception had operated: assimilation, causing TS up to $I=400 \mathrm{msec}$, and a mechanism that caused time order errors (TOEs; e.g., Allan, 1977; Hellström, 1985) from $I=400-1,600 \mathrm{msec}$.

Although Sasaki et al. (1992) convincingly demonstrated that TS is not confined only to two neighboring durations, it gave little insight into a potentially more intricate interaction between the three neighboring intervals. In their study, the variation of $I$, the empty duration separating $t 1$ and $t 2$, was very coarse, as compared with the magnitudes of these separated durations, and furthermore, $I$ was always longer than $t 2$. In addition to unilateral assimilation, Gestalt factors, such as the proximity of two markers in time or the similarity of two durations of the three neighboring intervals and figural aspects related to these factors, might occur if the duration of $I$ also takes values in the same range as those of $t 1$ and $t 2$.

Gestalt principles such as similarity and proximity are mainly known by their visual examples, but they also operate in auditory perception. The Gestalt psychologists were well aware of that. Wertheimer (1923), for instance, paid a lot of attention to the operation of Gestalt factors in auditory perception in a theoretical article. In this article, he showed that grouping by similarity and temporal proximity can also be observed in audition. Wertheimer, lacking the luxury of sound software and audio demonstration CDs available nowadays, demonstrated auditory Gestalt formation in front of his classrooms, in Frankfurt, with a violin and, in New York, with a clavier (Lück \& Miller, 1993). More recently, Bregman (1990) convincingly argued that the way humans organize their auditory scene can be well described in terms of Gestalt principles. Furthermore, Handel (1989) stated that "the rules that listeners use are analogous to those used for visual perception and are parallel to the classic Gestalt perceptual rules of similarity, proximity, good continuation, and so forth" (p. 217).
Our everyday experience that similarities and differences of time intervals in sound sequences give rise to perceptual grouping is studied in many articles (e.g., Fraisse, 1956; Jones \& Yee, 1993; Vos, 1973). Our purpose in the present study is to investigate how TS unfolds in temporal patterns consisting of three intervals and whether the mechanism of TS interacts with Gestalt principles.

\section{EXPERIMENT 1}

Like Sasaki et al. (1992), we used temporal patterns consisting of three neighboring empty durations, marked by four successive sound bursts. We were interested in what would happen to the subjective duration of the last interval when the preceding duration, called $I$ by Sasaki et al. (1992), took values comparable to those of $t 1$ and $t 2$. In the present study, we named the first duration $P 1$, the second duration $P 2$, and the last one $S$ (the standard duration to be matched). We fixed $P 1$, and varied $P 2$ and $S$ systematically.

\section{Method}

Participants. Six students from the department of music at Miyagi Gakuin Women's College (Sendai, Japan) participated in the experiment. Their ages ranged from 19 to 22 years, and they had normal hearing.

Materials and Design. There were three types of temporal patterns. The first type consisted of control patterns that included a single empty duration (the standard duration, $S$ ). Patterns of the second type included two neighboring empty durations ( $P 2$ and $S$ ). The third type comprised the experimental patterns consisting of three neighboring empty durations $(P 1, P 2$, and $S)$. The empty durations were marked by $3000-\mathrm{Hz}$ pure-tone bursts of $7 \mathrm{msec}$ including a rise and a fall time of about $1 \mathrm{msec}$ at about $90 \mathrm{dBA}$, measured as the level of a continuous tone of the same amplitude. $S$ was varied between $40,80,120$, and $160 \mathrm{msec}$ in all the conditions. In the /P2/S/ patterns, $P 2$ was varied between 40 and $480 \mathrm{msec}$ in steps of $40 \mathrm{msec}$. In the experimental patterns, $P 1$ was fixed at $40 \mathrm{msec}$ and $P 2$ was varied between 40,80, 120, 200, 280, 360, and $440 \mathrm{msec}$. The patterns were followed by a comparison time interval $(C)$ marked by the same tone bursts. The time elapsing between $S$ and $C$ was randomly varied between 1,800 and $2,200 \mathrm{msec}$. The initial value of $C$ was either clearly shorter (ascending series) or clearly longer (descending series) than $S$. Thus, one measurement block contained 2 (ascending/descending) $\times 80(4 / S /$ patterns +48 $/ P 2 / S /$ patterns $+28 / P 1 / P 2 / S /$ patterns) temporal patterns. A Commodore Amiga 500 computer was used to generate the stimuli, control the timing, and register the responses. The stimuli were presented via a bandpass filter (NF DV-04: 2800-3800 Hz), an amplifier (JVC AX-S900), and headphones (Stax SR $\lambda$ professional) to the participant's left ear.

Procedure. The task of the participant was to match the perceived duration of $C$ to that of $S$. The duration of $C$ could be changed by clicking the mouse button on "shorten" or "lengthen" adjustment panes on the monitor screen. The stimulus pattern was presented about $2 \mathrm{sec}$ after clicking the pane. The participant could change $C$ as many times as she wanted. After each change of $C$, the whole sound pattern, including the just-adjusted $C$, was presented. The final physical values of $C$, with which the participant was satisfied with the match to $S$, were recorded as the points of subjective equality (PSEs).

Each participant attended four sessions individually and did one measurement block per session, which lasted about $1 \mathrm{~h}$. The first block served as training; thus, six PSEs (three from ascending and three from descending series) remained from each participant for 
analysis for each stimulus pattern. Each block consisted of 160 trials in random order.

\section{Results and Discussion}

The average PSE for each pattern and participant was calculated. Figure 1 shows the mean PSEs of the /P2/S/ patterns and the mean control PSEs $(P 2=0 \mathrm{msec})$. We submitted the average PSEs of $S$ in the $/ P 2 / S /$ and in the corresponding $/ S /$ control conditions to a 4 ( $S$ durations) $\times$ 13 ( $P 2$ durations) repeated measures analysis of variance (ANOVA). The main effect of $S$ duration was, of course, artifactually significant $[F(3,15)=585.35, p<.001]$, because longer POEs of $S$ imply longer PSEs. Of interest was that the main effect of $P 2$ duration was significant $[F(12,60)=23.25, p<.001]$. The interaction effect was significant as well $[F(36,180)=9.38, p<.001]$.

As was expected, TS occurred in the $/ P 2 / S /$ patterns of /40/80/, /40/120/, /80/120/, /80/160/, and /120/160/. In these patterns, the difference between $S$ and $P 2$ is 40 or $80 \mathrm{msec}$. For those patterns in which $S-P 2$ exceeded $80 \mathrm{msec}$, TS did not occur. These results are completely in line with our previous results (e.g., ten Hoopen et al., 1993).

Figure 2 portrays the mean PSEs of $S$ in the /40/P2/S/ patterns, and for reference, the mean base rate PSEs of $S=40,80,120$, and $160 \mathrm{msec}$ are inserted as horizontal lines. We submitted the average PSEs per participant and per pattern to a 4 ( $S$ durations $) \times 8$ ( $P 2$ durations) repeated measures ANOVA. As above, the main effect of $S$ duration was, of course, artifactually significant $[F(3,15)=253.36$, $p<.001]$. The main effect of $P 2$ duration was significant
$[F(7,35)=19.32, p<.001]$, and the interaction was significant as well $[F(21,105)=9.66, p<.001]$.

Figure 2 shows the underestimation of $S$ to be remarkable in the patterns $/ 40 / 40 / 80 /, / 40 / 40 / 120 /$, and $/ 40 / 80 /$ $120 / \mathrm{msec}$. The amount of underestimation was $40 \mathrm{msec}$ or more in these patterns. Our very first interpretation, in view of Sasaki et al. (1992), was that assimilation had taken place between the first duration $P 1$ and the third duration $S$, with $P 2$ functioning as a separating duration between them. However, in these three patterns, the difference between $P 2$ and $S$ was also 40 or $80 \mathrm{msec}$, and therefore, $P 2$ was equally suitable to shrink the subjective duration of $S$. Unfortunately, the present combinations of $P 1, P 2$, and $S$ values did not allow us to determine whether $S$ assimilates either to $P 1$ or to $P 2$.

It was possible to infer from the data whether adding a $P 1$ of $40 \mathrm{msec}$ to those $/ P 2 / S /$ patterns in which $S$ was shrunk increased the amount of shrinking, as a comparison of Figures 1 and 2 suggested. We performed a $2(P 1$ absent/present $) \times 2(P 2=40$ or $80 \mathrm{msec}) \times 2(S=40$ or $80 \mathrm{msec}$ ) repeated measures ANOVA. The main effects of $P 2$ and $S$ were significant $[F(1,5)=57.75, p<.001$ and $F(1,5)=209.29, p<.001$, respectively], but far more informative was the significant main effect of having $P 1$ or $\operatorname{not}[F(1,5)=35.87, p<.002]$ in the direction that $S$ was underestimated more when $P 1$ was present. None of the three 2-way interactions was significant. The significant main effect of having $P 1$ or not may be due to two different causes (see Table 1 ). When $P 1$ equals $P 2$, a more vivid auditory image of the interval preceding $S$ might be formed by which $S$ is shrunk more strongly. The other cause for in-

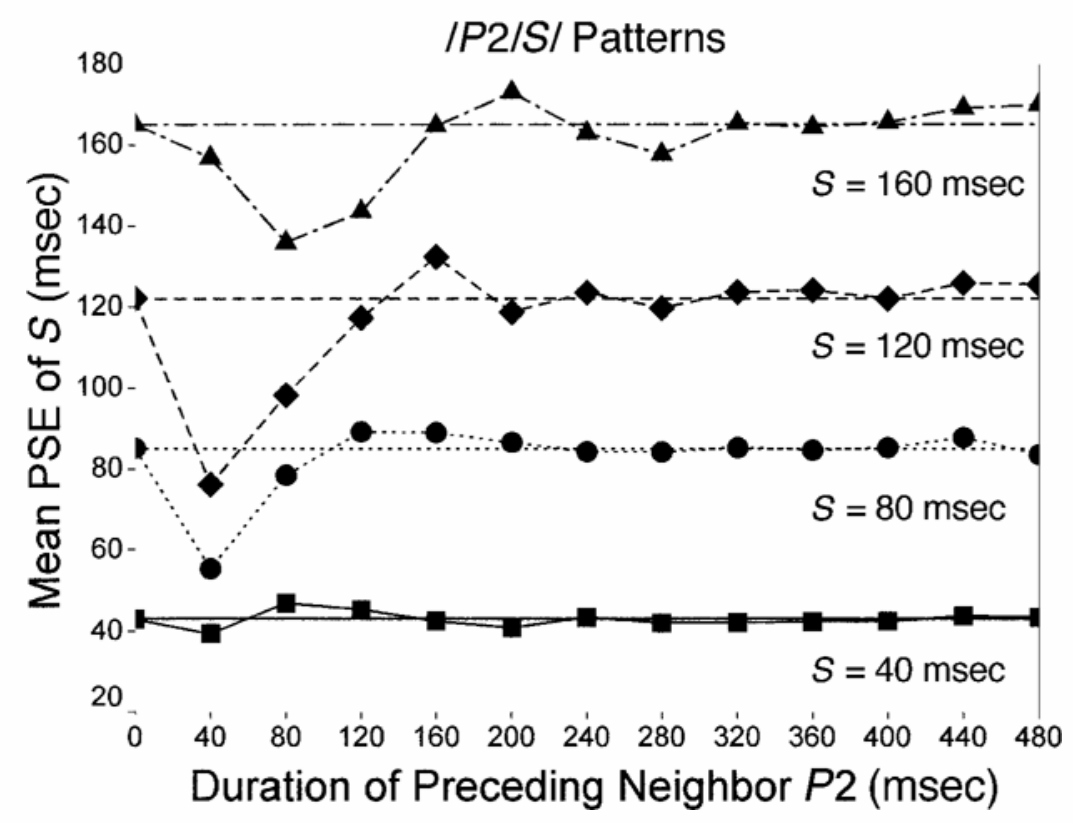

Figure 1. Mean points of subjective equality (PSEs) in Experiment 1 as a function of the durations of the standard time interval $(S)$ and the preceding neighbor interval $(P 2)$. For reference, the control PSEs of $S$ are drawn as horizontal lines. All values are in milliseconds. 


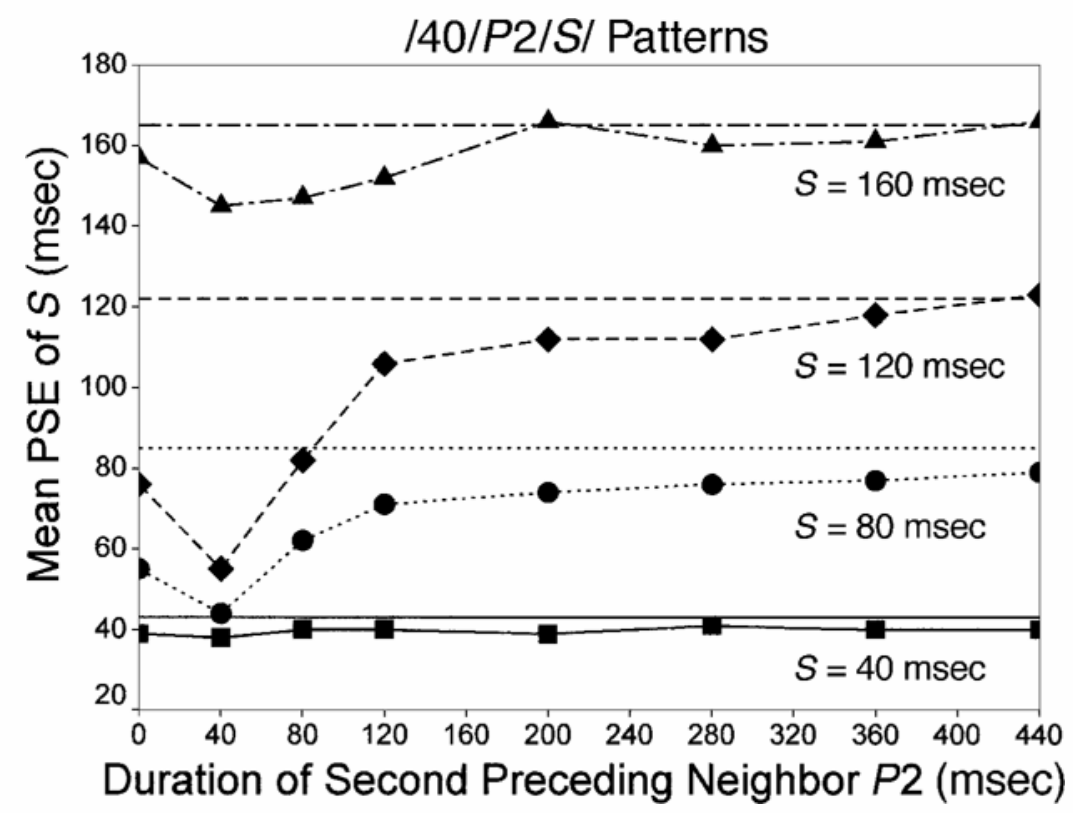

Figure 2. Mean points of subjective equality (PSEs) in Experiment 1 as a function of the durations of the standard time interval $(S)$ and the preceding neighbor time interval $(P 2)$ when the first preceding time interval $(P 1)$ was fixed at $40 \mathrm{msec}$. For reference, the control PSEs of $S$ are drawn as horizontal lines. All values are in milliseconds.

creased shrinking (in the /40/80/80/ and /40/80/120/ patterns) will be explained in Experiment 5 and in the General Discussion section.

\section{EXPERIMENT 2}

We designed this experiment to determine which of the first or the second durations, $P 1$ or $P 2$, has a dominant influence upon the underestimation of the last duration $S$ and to examine whether and how the first two durations interact in affecting the last one.

\section{Method}

Participants. Two female and three male students with normal hearing participated. They were students of acoustic design at the Kyushu Institute of Design (Fukuoka, Japan) and were 22-23 years of age. The students had received 2 years of training in technical listening for acoustic engineers and had played musical instruments for 3 years or more.

Materials and Design. In the control condition, an $S$ of 80, 160, or $240 \mathrm{msec}$ was presented (3 patterns). In the single-neighbor condition, $/ P 2 / S /$ patterns were presented, and all possible combinations of 80,160 , and $240 \mathrm{msec}$ were chosen as the physical durations of $P 2$ and $S$ (thus, 9 patterns). In the experimental two-neighbor condition, patterns of $/ P 1 / P 2 / S /$ were presented, and all possible combinations of 80,160 , and $240 \mathrm{msec}$ were chosen as the physical durations of $P 1, P 2$, and $S$ (thus, 27 patterns). In sum, there were 39 patterns, and because ascending and descending adjustments were required, a measurement block comprised $2 \times 39=78$ trials.

The empty durations were marked by 7-msec pure-tone bursts of $3000 \mathrm{~Hz}$, including a rise and a fall time of about $1 \mathrm{msec}$. The stimuli were generated and controlled by a Commodore Amiga 600 computer and were presented through a bandpass filter (NF DV-6BW:
2800-3800 Hz), an amplifier (JVC AX-Z511), and the left shell of headphones (AKG K141). The sound level of the marker signal was about $90 \mathrm{dBA}$ when presented continuously, as measured by a precision sound-level meter (Brüel \& Kjaer 2209), mounted with an artificial ear (Brüel \& Kjaer 4153) and a microphone (Brüel \& Kjaer 4134).

Procedure. After a training block, three blocks of measurements were conducted by each participant, in which the 39 patterns appeared for one trial each. The participant's task was to match the duration of $C$ to that of $S$ by operating a computer mouse. The first sound marker of the stimulus pattern started between 2,800 and $3,200 \mathrm{msec}$ after the participant triggered the presentation. This delay was varied randomly in this range. $C$ began between 3,800 and $4,200 \mathrm{msec}$ after the last marker of $S$. This time interval was also varied randomly. The change of $C$ could be controlled in steps of $1 \mathrm{msec}$, and there was no limit to the number of changes. After each change of $C$, the whole pattern and $C$ were presented. When the participant judged that the duration of $C$ was perceived as equal to that of $S$, he or she finished the trial. The final physical duration of $C$ was recorded as the PSE of $S$.

Table 1

Amounts of Underestimation (PSEexp - PSEcon, in Milliseconds) in Experiment 1 of the Standard

Empty Time Interval $(S=80$ or $120 \mathrm{msec})$ as a Function of the Number of Preceding Empty Time Intervals $(/ P 2 /$ or $/ P 1 / P 2 /)$ and of the Duration of $P 2(40$ or $80 \mathrm{msec})$

\begin{tabular}{cccc}
\hline$/ P 2 / \mathrm{S} /$ & PSEexp - PSEcon & $/ P 1 / P 2 / \mathrm{S} /$ & PSEexp - PSEcon \\
\hline$/ 40 / 80 /$ & -30 & $/ 40 / 40 / 80 /$ & -41 \\
$/ 80 / 80 /$ & -7 & $/ 40 / 80 / 80 /$ & -23 \\
$/ 40 / 120 /$ & -46 & $/ 40 / 40 / 120 /$ & -67 \\
$/ 80 / 120 /$ & -24 & $/ 40 / 80 / 120 /$ & -40 \\
\hline
\end{tabular}

Note-PSEexp, experimental point of subjective equality; PSEcon, control PSE. 
Table 2

Mean Points of Subjective Equality (PSEs) of the Standard Durations $S=80 \mathrm{msec}$ (Top), $S=160 \mathrm{msec}$ (Middle), and $S=$ $240 \mathrm{msec}$ (Bottom) in the Experimental (Single-Neighbor) Conditions (PSEexp) and in the Control Conditions (PSEcon) in Experiment 2 and Their Differences $(\Delta$ PSE $=$ PSEexp - PSEcon $)$

\begin{tabular}{ccccc}
\hline $\begin{array}{c}\text { Single-Neighbor } \\
\text { Condition }\end{array}$ & $\begin{array}{c}\text { Mean } \\
\text { PSEexp }\end{array}$ & $\begin{array}{c}\text { Control } \\
\text { Condition }\end{array}$ & $\begin{array}{c}\text { Mean } \\
\text { PSEcon }\end{array}$ & $\begin{array}{c}\boldsymbol{\Delta} \\
\text { PSE }\end{array}$ \\
\hline$/ 80 / 80 /$ & 79 & $/ 80 /$ & 83 & -4 \\
$/ 160 / 80 /$ & 90 & $/ 80 /$ & 83 & 7 \\
$/ 240 / 80 /$ & 85 & $/ 80 /$ & 83 & 2 \\
$/ 80 / 160 /$ & 120 & $/ 160 /$ & 156 & $-36^{*}$ \\
$/ 160 / 160 /$ & 160 & $/ 160 /$ & 156 & 4 \\
$/ 240 / 160 /$ & 145 & $/ 160 /$ & 156 & -11 \\
$/ 80 / 240 /$ & 262 & $/ 240 /$ & 254 & 8 \\
$/ 160 / 240 /$ & 214 & $/ 240 /$ & 254 & -40 \\
$/ 240 / 240 /$ & 258 & $/ 240 /$ & 254 & 4 \\
\hline
\end{tabular}

Note-All values are in milliseconds. *Significant $\Delta$ PSE.

\section{Results and Discussion}

For each of the 39 stimulus patterns, we obtained six PSEs of $S$ from each of the 5 participants. For each stimulus pattern, these six replications were averaged per participant. First, we compared the single neighbor patterns $/ P 2 / S /$ with the corresponding control patterns /S/ (see Table 2). The mean PSEs of $S=80 \mathrm{msec}$ in the singleneighbor $/ 80 / 80 /, / 160 / 80 /$, and $/ 240 / 80 /$ patterns $(79,90$, and $85 \mathrm{msec}$, respectively) and the mean PSE in the control /80/ pattern $(83 \mathrm{msec})$ did not differ from each other significantly, according to a one-way ANOVA $[F(3,12)=$ $2.44, p<.115]$.

The mean PSEs of $S=160 \mathrm{msec}$ in the single-neighbor /80/160/, /160/160/, and /240/160/ patterns $(120,160$, and $145 \mathrm{msec}$, respectively) and the mean PSE in the /160/ control pattern (156 msec) differed significantly according to a one-way ANOVA $[F(1.52,6.07)=8.64, p<.02$, degrees of freedom adjusted following GreenhouseGeisser]. Subsequently, we compared the mean PSE of $S=160 \mathrm{msec}$ in the $/ 80 / 160 /$ pattern, a pattern in which shrinking typically occurs, and the mean PSE in the /160/ pattern by a paired samples $t$ test. As was expected, the difference of $36 \mathrm{msec}$ was significant $[t(4)=3.16, p<$ .034].

The mean PSEs in the single-neighbor $/ 80 / 240 /, / 160 /$ $240 /$, and $/ 240 / 240 /$ patterns $(262,214$, and $258 \mathrm{msec}$, respectively) and the mean PSE in the $/ 240 /$ control pattern (254 msec) differed significantly according to a one-way ANOVA $[F(3,12)=4.45, p<.025]$. However, subsequent comparison of the PSEs of $S=240$ in the $/ 240 /$ pattern and the $/ 160 / 240 /$ pattern failed to reach significance $(p<.14)$. This was against our expectation, because $S$ in the /160/ $240 /$ pattern was almost always significantly and strongly underestimated in our previous studies. A closer inspection of the five individual mean PSEs in the /160/ 240/ pattern revealed that 4 participants had mean PSEs of 171 , 197,202 , and $226 \mathrm{msec}$ - that is, they underestimated $S=$ $240 \mathrm{msec}$ - but 1 participant overestimated it $(276 \mathrm{msec})$. As Suetomi and Nakajima (1998) have pointed out, such exceptional cases can be observed, although rarely.
The mean PSEs of $S$ in the two-neighbor $/ P 1 / P 2 / S /$ patterns are given in Table 3. A one-way ANOVA on the mean PSEs in the nine 2-neighbor patterns in which $S$ was $80 \mathrm{msec}$ and the mean PSE in the /80/ control pattern showed these 10 mean PSEs to differ significantly from each other $[F(2.46,9.85)=5.42, p<.022$, degrees of freedom adjusted following Greenhouse-Geisser]. Subsequent comparisons of the nine experimental patterns with the control revealed that none of the experimental PSEs differed significantly.

A one-way ANOVA on the mean PSEs in the nine 2neighbor patterns in which $S$ was $160 \mathrm{msec}$ and the mean PSE in the /160/ control pattern showed these 10 mean PSEs to differ significantly $[F(2.70,10.79)=6.02, p<$ .013 , degrees of freedom adjusted following GreenhouseGeisser]. Of the nine experimental patterns that were compared with the control, three differed significantly. The duration was underestimated by $43 \mathrm{msec}$ of $S$ in the $/ 80 / 80 / 160 /$ pattern $[t(4)=2.74, p<.05]$, by $25 \mathrm{msec}$ in the $/ 160 / 80 / 160 /$ pattern $[t(4)=3.32, p<.03]$, and by $49 \mathrm{msec}$ in the $/ 240 / 80 / 160 /$ pattern $[t(4)=5.06, p<.01]$. These three patterns fulfill the temporal relationship $S-$ $P 2=80 \mathrm{msec}$, for which it has been established in single-neighbor patterns that TS is approximately at maximum (e.g., ten Hoopen et al., 1993). Only in the /80/80/ $160 /$ pattern was $S-P 1$ also $80 \mathrm{msec}$, and $P 1$ could have

Table 3

Mean Points of Subjective Equality (PSEs) of the Standard Durations $S=80 \mathrm{msec}$ (Top), $S=160 \mathrm{msec}$ (Middle), and $240 \mathrm{msec}$ (Bottom) in the Experimental (Two-Neighbor) Conditions in Experiment 2 and their Differences with the Control PSE of $S$ ( $\triangle$ PSE = PSEexp - PSEcon $)$.

\begin{tabular}{|c|c|c|}
\hline $\begin{array}{c}\text { Two-Neighbor } \\
\text { Condition }\end{array}$ & $\begin{array}{c}\text { Mean } \\
\text { PSE }\end{array}$ & $\begin{array}{c}\Delta \\
\mathrm{PSE}\end{array}$ \\
\hline$/ 80 / 80 / 80 /$ & 72 & -11 \\
\hline$/ 80 / 160 / 80 /$ & 82 & -1 \\
\hline$/ 80 / 240 / 80 /$ & 77 & -6 \\
\hline$/ 160 / 80 / 80 /$ & 78 & -5 \\
\hline$/ 160 / 160 / 80 /$ & 80 & -3 \\
\hline$/ 160 / 240 / 80 /$ & 84 & 1 \\
\hline$/ 240 / 80 / 80 /$ & 80 & -3 \\
\hline$/ 240 / 160 / 80 /$ & 94 & 11 \\
\hline$/ 240 / 240 / 80 /$ & 86 & 3 \\
\hline$/ 80 / 80 / 160 /$ & 113 & $-43 *$ \\
\hline$/ 80 / 160 / 160 /$ & 141 & -15 \\
\hline$/ 80 / 240 / 160 /$ & 145 & -11 \\
\hline$/ 160 / 80 / 160 /$ & 131 & $-25^{*}$ \\
\hline$/ 160 / 160 / 160 /$ & 154 & -2 \\
\hline$/ 160 / 240 / 160 /$ & 155 & -1 \\
\hline$/ 240 / 80 / 160 /$ & 107 & $-49 *$ \\
\hline$/ 240 / 160 / 160 /$ & 149 & -7 \\
\hline$/ 240 / 240 / 160 /$ & 147 & -9 \\
\hline$/ 80 / 80 / 240 /$ & 248 & -6 \\
\hline$/ 80 / 160 / 240 /$ & 263 & 9 \\
\hline$/ 80 / 240 / 240 /$ & 262 & 8 \\
\hline$/ 160 / 80 / 240 /$ & 255 & 1 \\
\hline$/ 160 / 160 / 240 /$ & 237 & -17 \\
\hline$/ 160 / 240 / 240 /$ & 249 & -5 \\
\hline$/ 240 / 80 / 240 /$ & 270 & 16 \\
\hline$/ 240 / 160 / 240 /$ & 273 & 19 \\
\hline$/ 240 / 240 / 240 /$ & 258 & 4 \\
\hline
\end{tabular}

Note-All values in milliseconds. • Significant $\Delta$ PSE. 
caused the underestimation equally well. If the influence of $P 1$ were dominant, however, there would have occurred shrinking of $S$ in the /80/160/160/ and /80/240/160/ patterns likewise, which was not the case. We suppose that the influence of $P 2$ is dominant in the underestimation of the last duration in the two-neighbor condition.

A one-way ANOVA on the mean PSEs in the nine 2neighbor patterns in which $S$ was $240 \mathrm{msec}$ and the mean PSE in the /240/ control pattern, showed that these 10 mean PSEs did not differ significantly from each other $[F(2.26,9.04)=2.21, p<.16$, degrees of freedom adjusted following Greenhouse-Geisser].

In conclusion, when $P 1, P 2$, and $S$ were neighbors of each other in this order, $S$ could be underestimated, depending on the temporal relationship between these empty durations. Thus, TS also appears to operate in temporal patterns one step more complex (three neighboring durations) than the temporal patterns in our previous studies (two neighboring durations). The influence of $P 2$ on the perception of $S$ seemed dominant, but it could be modulated by $P 1$. The influence of $P 1$ will be the topic of the following experiments.

\section{EXPERIMENT 3}

Experiment 2 showed that the final duration $S$ could be underestimated in several cases in which $S-P 2=80 \mathrm{msec}$. We could, however, not easily determine interactive effects of $P 1$, owing to the way $P 1$ was covaried with $P 2$ and $S$. Therefore, in this experiment, the difference between $S$ and $P 2$ was fixed at $80 \mathrm{msec}$, and $P 1$ was varied in smaller steps and across a wider range of durations.

\section{Method}

Participants. Two female and 3 male students of acoustic design at the Kyushu Institute of Design, 21-23 years of age, participated. They had normal hearing and received 2 years of training in technical listening for acoustic engineers and had played musical instruments for 6 years or more.

Materials and Design. We used the same type of stimulus patterns as that in Experiments 1 and 2. The physical duration of $S$ in the control condition was 200 or $280 \mathrm{msec}$, the single-neighbor conditions /P2/S/ were /120/200/ and /200/280/ msec, and the patterns $/ P 1 / 120 / 200 /$ and $/ P 1 / 200 / 280 \mathrm{msec}$ were employed in the twoneighbor condition. The physical duration of $P 1$ was $40,80,120,160$, $200,240,280,320$, or $400 \mathrm{msec}$ in the patterns $/ P 1 / 120 / 200 / \mathrm{msec}$, and $40,80,120,160,200,240,280,320,360,400$, or $480 \mathrm{msec}$ in the patterns $/ P 1 / 200 / 280 /$ msec.

Thus, there were 2 patterns in the control condition, 2 patterns in the single-neigh bor condition, and 20 patterns in the two-neighbor condition. In total, 48 trials [24 (patterns) $\times 2$ (ascending/descending)] made a measurement block. Four blocks of measurements were conducted for each participant, and the last three blocks were analyzed as data. The apparatus and other aspects of the procedure were the same as those in Experiment 2.

\section{Results and Discussion}

The mean PSEs for each of the temporal patterns in which $S$ was $200 \mathrm{msec}$ are displayed in Figure 3. To test whether the seemingly immense amount of modulation by $P 1$ upon the shrinking of $S$ by $P 2$ was significant, we ran a one-way repeated measures ANOVA on the averaged PSEs of the 5 participants. The mean PSEs of $S$ in the 11

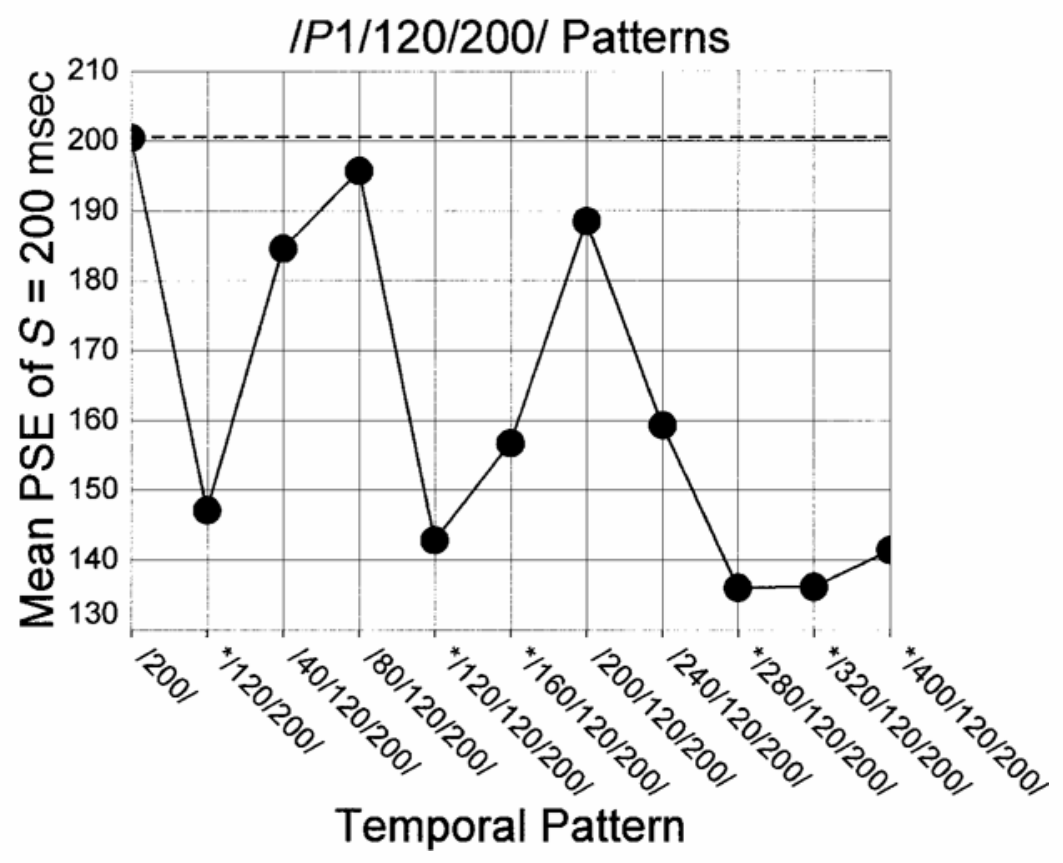

Figure 3. Mean points of subjective equality (PSEs) in Experiment 3 as a function of the duration of the first preceding time interval $(P 1)$. The second preceding time interval $(P 2)$ and the standard time interval $(S)$ are fixed at 120 and $200 \mathrm{msec}$, respectively. For reference, the control PSE of $S=200 \mathrm{msec}$ is drawn as a horizontal dashed line. In tem poral patterns marked by asterisks, $S$ is shrunk significantly. All values are in milliseconds. 
temporal patterns differed significantly from each other $[F(1.63,6.53)=15.55, p<.004$, degrees of freedom adjusted following Greenhouse-Geisser]. To test whether TS occurred or not in the 10 candidate patterns for shrinking (/120/200/ and /40/120/200/ through /400/120/200/), we compared them with the $/ 200 /$ control pattern. We chose a per family error rate of .05 , and following the Bonferonni method, the level for each of the 10 paired sample $t$ tests was set at $.05 / 10=.005$.

As was expected, shrinking of $S=200 \mathrm{msec}$ in the pattern $/ 120 / 200 /$ by an amount of $53 \mathrm{msec}$ was significant. In the patterns $/ 40 / 120 / 200 /$ and $/ 80 / 120 / 200 /$, the PSEs of $S$ did not differ from the control PSE, even though the relation between $P 2$ and $S$ was suitable for shrinking to occur. We conjecture that in the /40/120/200/ and /80/120/ $200 /$ patterns, $P 2$ itself is shrunk by $P 1$ because the temporal relationship $P 2-P 1 \leq 80 \mathrm{msec}$ fulfills the requirements for TS to take place. If this were the case, the subjective duration of $P 2$ might be considerably shorter than that corresponding to $120 \mathrm{msec}$, and as a consequence the effective difference between $S$ and $P 2$ might be too large $(>80 \mathrm{msec})$ to cause TS. In Experiment 4, we will test this inference by requiring participants to match $C$ to $P 2$ directly in $/ P 1 / P 2 / \mathrm{S} /$ patterns.

Significant shrinking of $S$ was observed in the patterns /120/120/200/ and /160/120/200/. In these patterns, either $P 1$ or $P 2$ could have caused the underestimation of $S$, but given that the underestimationsdid not differ significantly from each other and did not differ from that in the /120/ 200 / pattern, it seems plausible that $P 2$ shrank $S$. As Figure 3 shows, the amounts of shrinking of $S=200 \mathrm{msec}$ in the patterns $/ 120 / 200 /$ and $/ 120 / 120 / 200 /$ did not differ. This result deviates from the finding in Experiment 1 that increasing the number of (equal) preceding intervals from one to two caused a significant increase of TS (see Table 1, compare patterns /40/80/ and /40/40/80/ and patterns $/ 40 / 120 /$ and $/ 40 / 40 / 120 /$ ). We hinted at the possibility that this increase arose because two equal preceding intervals formed a more vivid auditory image than one and, therefore, exerted a stronger shrinking force on $S$. The present result suggests that there is a temporal limit to this enhancing effect, and data by Remijn et al. (1999) support this suggestion. They varied the number of preceding intervals from one to five. When $P$ was $50 \mathrm{msec}$, and $S$ was $100 \mathrm{msec}$, there was a trend of increased shrinking with an increasing number of $P$ s, although the effect was not significant. For longer values of $P$ and $S$, this trend disappeared.

Curiously, no significant shrinking of $S=200 \mathrm{msec}$ occurred in the $/ 200 / 120 / 200 /$ and $/ 240 / 120 / 200 /$ patterns, even though the relationship $S-P 2=80 \mathrm{msec}$ was optimal for shrinking to occur. A possible explanation is in terms of the figural aspects of the pattern (Handel, 1992,1993). Detecting a similarity of the durations, the first two sound markers may be grouped together, and the last two sound markers may be grouped together as well. Because the two middle markers were allocated to these groups, the second one closing the first group and the third one starting the second group, the percept of the duration of $P 2$ was not clear enough, and it is unlikely that $P 2$ could shrink $S$. It seems that TS can be overruled by Gestalt principles.

If our explanation of the modifying effect of $P 1$ is viable, it should hold equally well for the $/ P 1 / 200 / 280 /$ conditions. Figure 4 displays the influence of $P 1$ on the base rate amount of underestimation of $47 \mathrm{msec}$, as was found in the $/ 200 / 280 /$ pattern. In this figure, it can be seen that the underestimation of $S$ strongly diminishes, or even changes into overestimations, when $P 1$ takes values of 40-320 msec. A one-way ANOVA on the mean PSEs of $S$ in the 13 temporal patterns showed that they differed significantly from each other $[F(2.40,9.60)=17.11, p<$ .001 , degrees of freedom adjusted following GreenhouseGeisser].

To test whether TS occurred or not in the 12 candidate patterns for shrinking (/200/280/ and /40/200/280/ through /480/200/280/), we compared them with the /280/ control pattern. We chose a per family error rate of .05 , and following the Bonferonni method, the level for each of the 12 paired sample $t$ tests was set at $.05 / 12=.004$. Significant shrinking of $S=280 \mathrm{msec}$ occurred in the pattern /200/ $280 /$, as was to be expected, and in the patterns $/ 360 / 200 /$ $280 /, / 400 / 200 / 280 /$, and /480/200/280/. It is hard to come up here with a reasonable explanation of why TS did not occur in the patterns /40/200/280/ and /80/200/280/, but we will return to the matter in Experiment 4 and in the General Discussion section.

For the fact that no underestimation of $S$ was found in the patterns /120/200/280/ and /160/200/280/, we have the same surmise as was made above with the $/ 40 / 120 / 200 /$ and /80/120/200/ patterns. It is quite likely that $P 2$ was shrunk by $P 1$, yielding effective differences between $S$ and $P 2$ too large $(>80 \mathrm{msec})$ for shrinking to operate. This possibility will be tested in Experiment 4 by measuring PSEs of $P 2$.

Although the underestimations were about $25 \mathrm{msec}$ in the patterns $/ 200 / 200 / 280 /$ and $/ 240 / 200 / 280 /$, they did not reach significance, whereas the underestimations in the comparable patterns /120/120/200/ and /160/120/200/ were significant. However, it is possible that some underestimations really appeared in these conditions, as will be indicated in a comparable condition in Experiment 5.

The lack of significant underestimation of $S$ in the patterns $/ 280 / 200 / 280 /$ and $/ 320 / 200 / 280 /$ might be explained in the same vein as that for the patterns /200/120/200/ and /240/120/200/. That is, figural aspects probably overruled TS.

\section{EXPERIMENT 4}

In Experiment 3, we supposed that $S=280 \mathrm{msec}$ in the patterns /120/200/280/ and /160/200/280/ was not shrunk because $P 2$ itself was already shrunk by $P 1$ and, hence, the difference $S-P 2$ was too large $(>80 \mathrm{msec})$ for shrinking of $S$ to occur. The present experiment was set up to test this conjecture by requiring the participants to match $C$ to $P 2$. Experiment 3 also showed that $S$ was not 


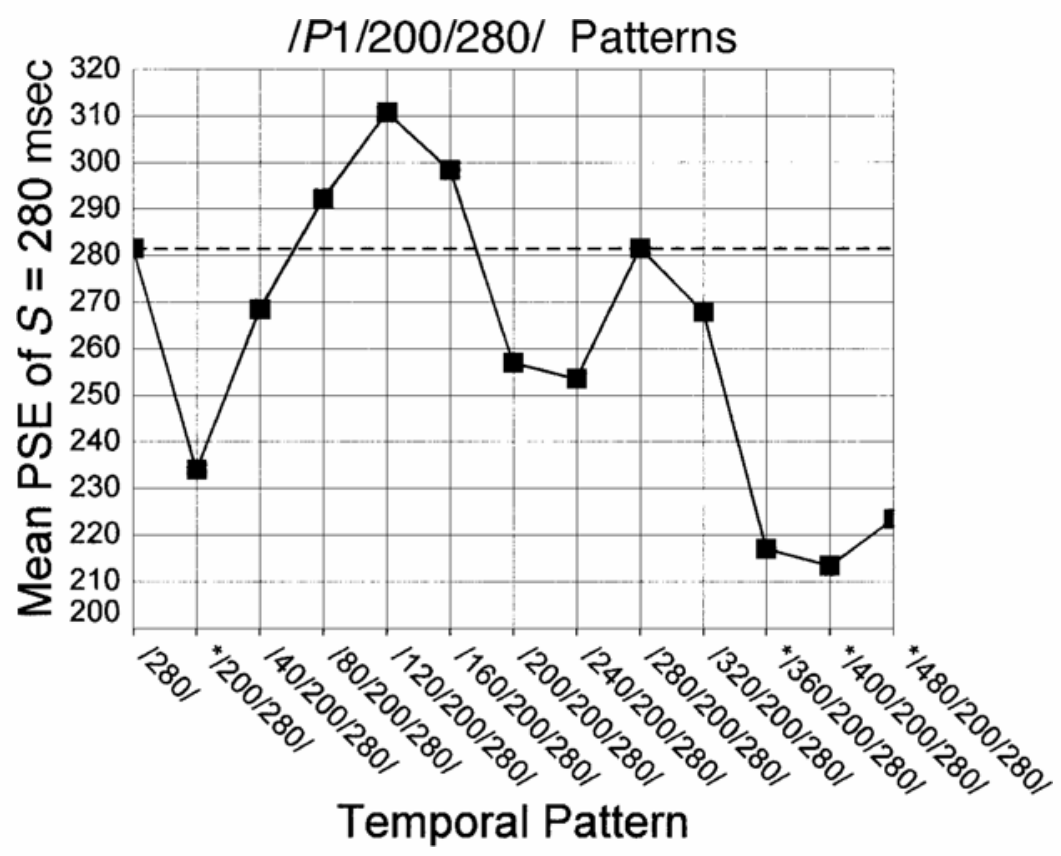

\begin{abstract}
Figure 4. Mean points of subjective equality (PSEs) in Experiment 3 as a function of the duration of the first preceding time interval $(P 1)$. The second preceding time interval $(P 2)$ and the standard time interval $(S)$ are fixed at 200 and $280 \mathrm{msec}$, respectively. For reference, the control PSE of $S=280 \mathrm{msec}$ is drawn as a horizontal dashed line. In temporal patterns marked by asterisks, $S$ is shrunk significantly. All values are in milliseconds.
\end{abstract}

shrunk in the patterns /40/200/280/ and /80/200/280/. This was against our expectation, because $S-P 2$ was $80 \mathrm{msec}$ and $P 2-P 1$ was theoretically too large $(>80 \mathrm{msec})$ for shrinking of $P 2$ to happen. We included these patterns here again but required the participants this time to match $C$ to $P 2=200 \mathrm{msec}$, to inspect the possibility that $P 2$ could be underestimated or overestimated.

\section{Method}

Participants. Six students, 4 male and 2 females 21-24 years of age, at the Kyushu Institute of Design served in the experiment. They had normal hearing, had received 2 years of training in technical listening for acoustic engineers, and had played musical instruments for 2 years or more.

Materials and Design. A control pattern of $/ 200 / \mathrm{msec}$ was employed, as well as four two-neighbor patterns: /40/200/280/, /80/200/ $280 /, / 120 / 200 / 280 /$, and $/ 160 / 200 / 280 / \mathrm{msec}$. This time, the participant was required to match the duration of the comparison $(C)$ to the second duration $P 2$ instead of to the last duration; thus, $P 2$ was the standard now. Six PSEs were obtained from each participant for each stimulus pattern. Other aspects of the method were comparable to those in the previous experiments.

\section{Results and Discussion}

Because this was the first time we required participants to adjust $C$ to the middle duration in two-neighbor patterns, we submitted the PSEs first to an exploratory data analysis. Figure 5 displays the boxplots of the control pattern and the 4 two-neighbor patterns. It is clear from this figure that the variability of the PSEs of $200 \mathrm{msec}$ in the
/40/200/280/ and /80/200/280/ patterns was extremely high, as compared with that in the other patterns. This means that the listeners must have had severe difficulty in judging the duration of $P 2$ in these patterns. We should admit, however, that it is difficult to grasp why the participants could not easily judge the middle duration in these patterns. A possible explanation will be offered in the General Discussion section.

Figure 5 also shows that the PSEs of $P 2$ in the patterns /120/200/280/ and /160/200/280/ are smaller than those of the control PSE, supporting our surmise that $P 1$ shrank $P 2$. To test whether the underestimations of $P 2$ were significant, we averaged the six replications of each participant and submitted these averages to paired sample $t$ tests. The difference between the mean control PSE (202 msec) and the mean PSE of $P 2$ in the /120/200/280/ pattern $(149 \mathrm{msec})$ was significant $[t(5)=13.37, p<.001]$. The difference between the mean control PSE (202 msec) and the mean PSE of $P 2$ in the $/ 160 / 200 / 280 /$ pattern $(177 \mathrm{msec})$ was significant as well $[t(5)=4.33, p<.01]$.

Because $P 2$ was shrunk by $53 \mathrm{msec}$ and $25 \mathrm{msec}$ in the $/ 120 / 200 / 280 /$ and $/ 160 / 200 / 280 /$ patterns, respectively, the effective differences between $S$ and $P 2$ in these patterns were larger than $100 \mathrm{msec}$ and could be too large to cause an underestimation of the third duration. Thus, our supposition in Experiment 3 that $P 1$ could have shrunk the duration of $P 2$ and, hence, could have had an indirect influence on the perception of $S$ is supported by the present data. 


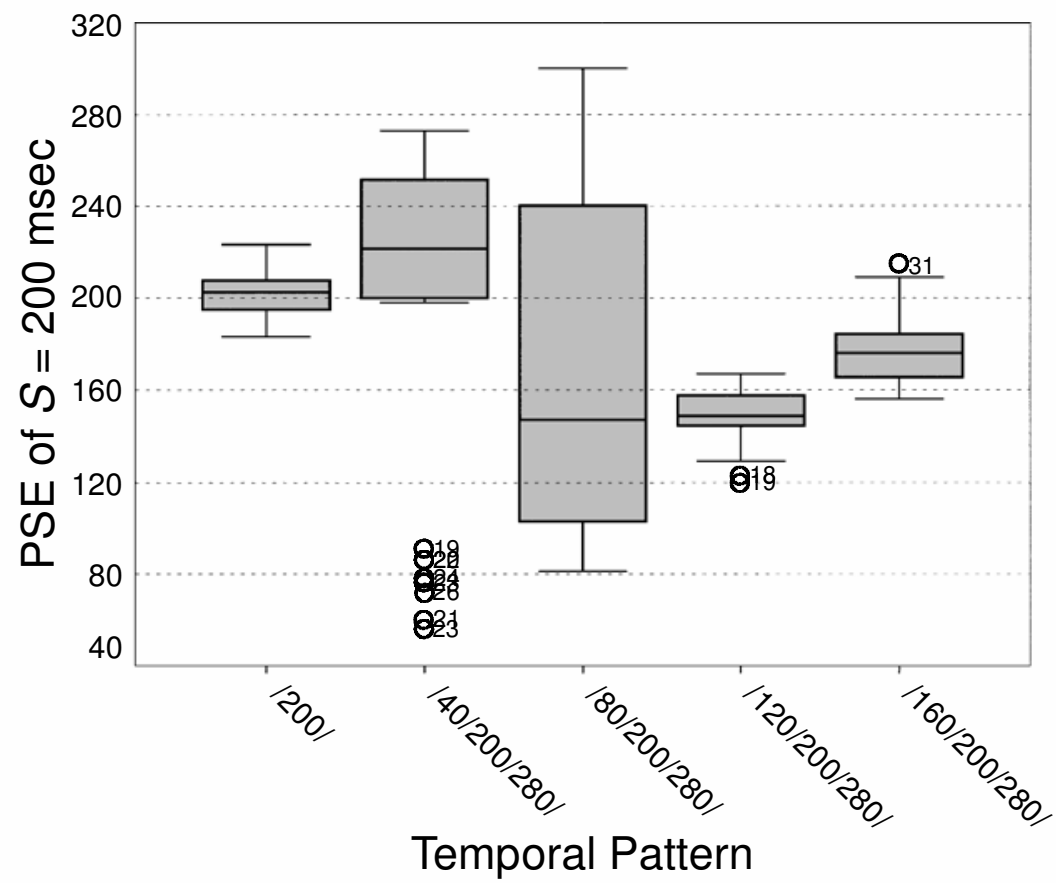

Figure 5. Boxplots, each based on 36 individual points of subjective equality (PSEs) of $S=200 \mathrm{msec}$, of the five temporal patterns studied in Experiment 4 . The leftmost boxplot represents the control temporal pattern $(/ 200 / \mathrm{msec})$. In the four experimental temporal patterns, the middle interval of $200 \mathrm{msec}$ had to be matched. Note the many outliers in the $/ 40 / 200 / 280 /$ pattern.

\section{EXPERIMENT 5}

In the previous experiments of this study, it was shown that $P 1$ either had a direct effect on the percept of the final interval or exerted an indirect effect via $P 2$. This final experiment was designed to study the direct influence of $P 1$ on the perception of the final duration more clearly. We fixed the difference between $S$ and $P 1$ at $80 \mathrm{msec}$ and varied $P 2$ in small steps over a wide duration range.

\section{Method}

Participants. Five participants with normal hearing, 2 female and 3 male students at the Kyushu Institute of Design, were employed. They were $21-24$ years of age, had received 2 years of training in technical listening for acoustic engineers, and had played musical instruments for 2 years or more.

Materials and Design. In the control condition, the same stimulus patterns as those in Experiment 3 (/200/ and /280/ msec) were used, and the single-neighbor condition consisted of the patterns $/ 120 / 200 /$ and $/ 200 / 280 / \mathrm{msec}$. In the two-neighbor condition, the patterns $/ 120 / P 2 / 200$ and $/ 200 / P 2 / 280 /$ msec were used. The physical durations of $P 2$ employed were the same as those employed for $P 1$ in Experiment 3; thus, 40, 80, 120, 160, 200, 240, 280, 320, and $400 \mathrm{msec}$ in the patterns $/ 120 / P 2 / 200 / \mathrm{msec}$, and $40,80,120,160$, $200,240,280,320,360,400$, and $480 \mathrm{msec}$ in the patterns $/ 200 / P 2 /$ $280 / \mathrm{msec}$. The rest of the method was the same as that in Experiment 3 .

\section{Results and Discussion}

The mean PSEs for each of the temporal patterns in which $S$ was $200 \mathrm{msec}$ are displayed in Figure 6. To test whether the seemingly huge variation between patterns was significant, we ran a one-way repeated measures ANOVA on the averaged PSEs of the 5 participants. The mean PSEs of $S$ in the 11 temporal patterns differed significantly from each other $[F(1.73,6.93)=8.53, p<$ .015 , degrees of freedom adjusted following GreenhouseGeisser]. To test whether TS occurred or not in the 10 candidate patterns for shrinking (/120/200/ and /120/40/200/ through/120/400/200/), we compared them with the /200/ control pattern. We chose a per family error rate of .05 , and following the Bonferonni method, the level for each of the 10 paired sample $t$ tests was set at $.05 / 10=.005$.

As was expected from previous studies, $S=200 \mathrm{msec}$ in the pattern /120/200/ was shrunk significantly by an amount of $55 \mathrm{msec}$, almost the same amount as in Experiment $3(53 \mathrm{msec})$. The other patterns in which significant underestimations of $S$ occurred were /120/120/200/, /120/160/200/, and /120/200/200/. In the pattern /120/ $120 / 200 /$, either $P 1$ or $P 2$ could have shrunk $S$. The shrinking of $S$ in the pattern /120/160/200/ could, in principle, have been caused by either $P 1$ or $P 2$. At first view, the large amount of underestimation of about $69 \mathrm{msec}$ seems to indicate that $P 1$ caused the underestimation. There is, however, another interesting explanation. In Experiment 4, we demonstrated that $P 1$ could shrink $P 2$; so, in the present pattern, it is plausible that a propagation of TS has taken place: $P 1$ shrank $P 2$, which in turn shrank $S$ more strongly because its effective difference with $S$ got bigger. In the pattern $/ 120 / 200 / 200 /$, the difference between $S$ and 


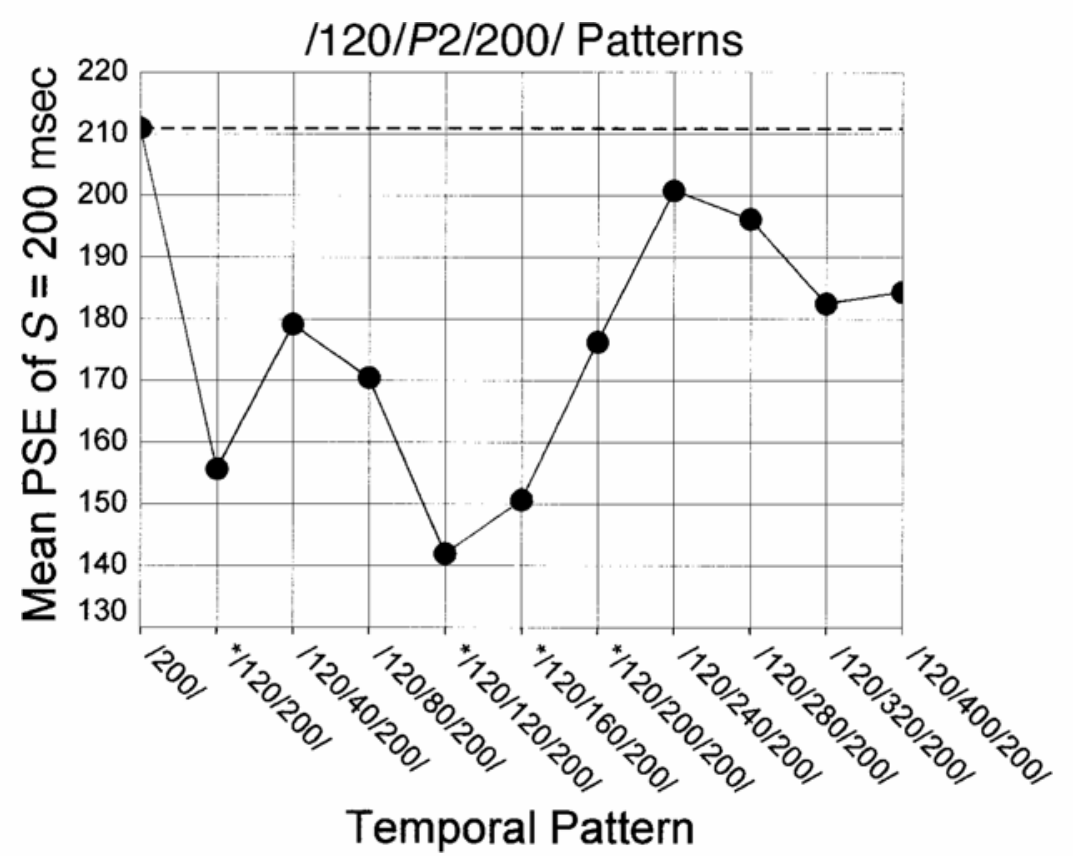

Figure 6. Mean points of subjective equality (PSEs) in Experiment 5 as a function of the duration of the second preceding time interval $(P 2)$. The first interval $(P 1)$ and the standard $(S)$ are fixed at 120 and $200 \mathrm{msec}$, respectively. For reference, the control PSE of $S=200 \mathrm{msec}$ is drawn as the dashed horizontal line. All values are in milliseconds.

$P 2$ was zero. Nevertheless, $S$ was underestimated in this pattern by $35 \mathrm{msec}$; thus, here we also have a case of propagation of TS from $P 1$ to $P 2$ to $S$.

The mean PSEs for each of the temporal patterns in which $S$ was $280 \mathrm{msec}$ are displayed in Figure 7. To test whether the seemingly huge variation between patterns was significant, we ran a one-way repeated measures ANOVA on the averaged PSEs of the 5 participants. The mean PSEs of $S$ in the 13 temporal patterns differed significantly from each other $[F(1.89,7.56=6.26, p<.026$, degrees of freedom adjusted following GreenhouseGeisser]. To test whether TS occurred or not in the 12 candidate patterns for shrinking (/200/280/, and /200/40/280/ through $/ 200 / 480 / 280 /$ ), we compared them with the $/ 280 /$ control pattern. We chose a per family error rate of .05 , and following the Bonferonni method, the level for each of the 12 paired sample $t$ tests was set at $.05 / 12 \simeq .004$.

The patterns in which significant underestimations of $S$ occurred were, as was expected, the one-neighbor pattern /200/280/ (47-msec underestimation). Of the two-neighbor patterns, significant shrinking took place only in $/ 200 /$ 200/280/ and $/ 200 / 480 / 280 /$. In the pattern $/ 200 / 200 / 280 /$, either $P 1$ or $P 2$ could have caused the shrinking of $S$. In the pattern $/ 200 / 480 / 280 /, P 2$ was far longer than $S$, so it must have been $P 1$ that directly shrank $S$.

\section{GENERAL DISCUSSION}

The present five experiments showed, not unexpectedly, that the temporal interaction between three neigh- boring empty durations is more complex than that between two durations. The simplest observation was that TS of the last interval could occur also when it was preceded by two intervals instead of one. We already had demonstrated this to be the case in a previous study (Remijn et al., 1999), in which the number of intervals preceding the final one was varied between one and five. However, Remijn et al.'s study applied only constant durations within the preceding series of intervals. The present study obtained a more detailed view of temporal interactions by systematically varying the values of three successive interval durations.

\section{Propagation of Time-Shrinking}

It turned out that TS takes place between the last two time intervals also when three time intervals are neighbors to each other, as in the present study. An interesting aspect is that TS does not seem to be confined to the last interval of a temporal pattern. We showed in Experiment 4 that the first duration, $P 1$, could shrink $P 2$. That suggests that shrinking can, in principle, propagate through patterns like $/ 120 / 160 / 200 /$. Because $P 1$ shrinks $P 2$, the effective difference between $S$ and $P 2$ becomes larger, and $S$ is shrunk more. This also explains that in patterns such as /120/ $200 / 200 /$, the last interval $S$ is shrunk clearly, even though $S-P 2=0$ msec. The fact that $P 1$ can shrink $P 2$ might also cancel TS: If $S-P 2$ is fixed at $80 \mathrm{msec}$, and $P 1$ shrinks $P 2$, the effective difference between $S$ and $P 2$ becomes too large for $S$ to be shrunk. An example is the pattern /80/120/200/. Thus, in general, the propagating effect 


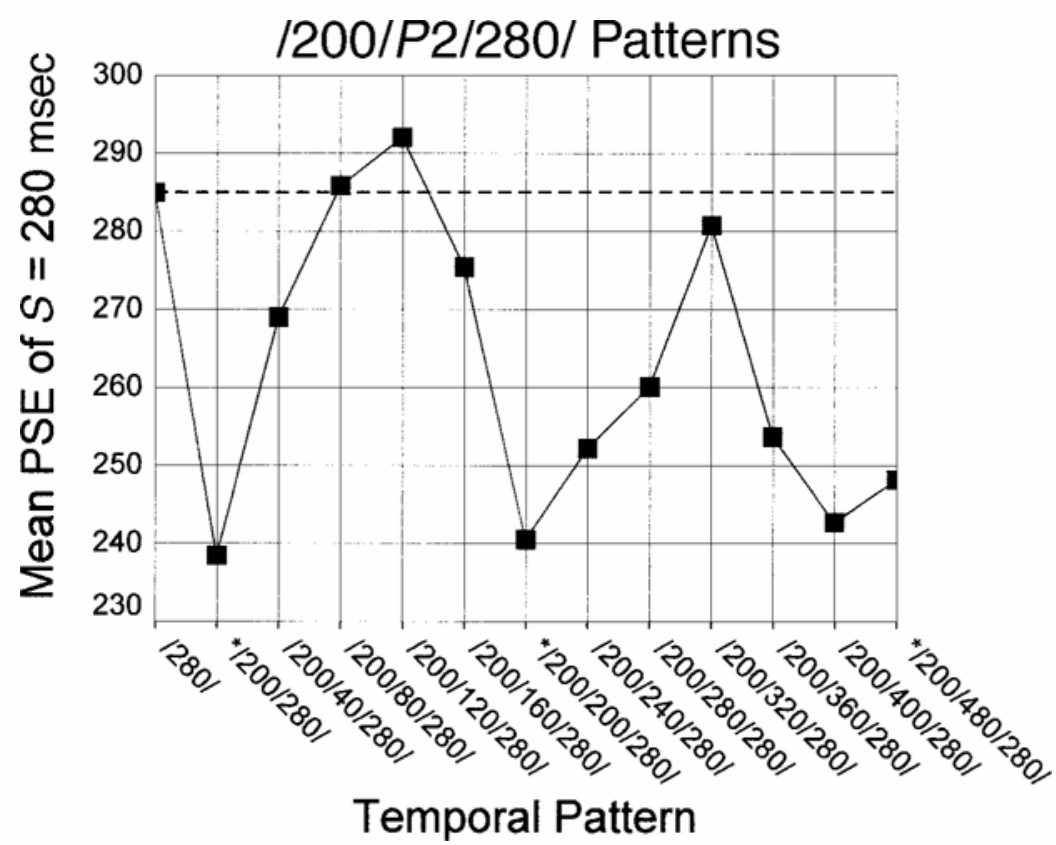

Figure 7. Mean points of subjective equality (PSEs) in Experiment 5 as a function of the duration of the second preceding time interval $(P 2)$. The first interval $(P 1)$ and the standard $(S)$ are fixed at 200 and $280 \mathrm{msec}$, respectively. For reference, the control PSE of $S=280 \mathrm{msec}$ is drawn as a dashed horizontal line. All values are in milliseconds.

of TS through the pattern can modulate the underestimation of the last interval. We surmise that the mechanism might work at any position in longer sequences as well, but we have no empirical evidence as yet.

\section{Temporal Proximity of Sound Markers}

In the patterns $/ 40 / 200 / 280 /$ and $/ 80 / 200 / 280 /$, the disappearance of underestimation of $S$ could not be explained by propagating TS. In these cases, $P 1$ was too short to shrink $P 2$. We suppose that the Gestalt principle of temporal proximity (Handel, 1992,1998; Povel \& Okkerman, 1981; Ross \& Houtsma, 1994) is useful for understanding the disappearance of underestimation in the following way. Because the first and the second sound markers embracing $P 1$ were very close to each other, this grouping could have had a strong figural aspect. We surmise that according to the rule of "belongingness" (e.g., Metzger, 1953) or "exclusive allocation" (Bregman, 1990), the second sound marker was captured strongly in this grouping and, hence, was not available any more to form a figural grouping embracing $P 2$. As a consequence, the auditory representation of the duration of $P 2$ might have become too vague to shrink $S$. Figure 5 convincingly portrays the huge instability of $P 2$ in the concerned patterns.

\section{Similarity of Durations}

When $P 1>P 2$ and the difference between $S$ and $P 2$ was ideal to cause shrinking of $S$, the underestimation of $S$ took place in most cases, except when $P 1 \approx \mathrm{S}$, and it vanished. Evidently, other temporal factors overruled the TS mechanism when $P 1 \simeq S$. A plausible description we can come up with is in terms of the Gestalt principle of similarity of durations. We suppose that because of the similarity between $P 1$ and $S$ in such patterns as $/ 200 /$ $120 / 200 /$ and $/ 280 / 200 / 280 /$, the figural grouping of the first two sound markers and that of the last two sound markers might be facilitated. As a result, the duration percept of $P 2$ becomes too weak to shrink $S$.

\section{Is Time-Shrinking a Reflection of the Time Order Error?}

We are perhaps in a better position now to treat the question whether TS, coined a new illusion by us in Nakajima et al. (1992), really deserves that label or should, rather, have been interpreted as a kind of TOE in the time domain, as Allan and Gibbon (1994) have argued. The first thing to be noted is that TOE is a stimulus presentation order effect found across almost all sensory modalities and dimensions, first reported by Fechner (1860/1966) in his research on lifted weights. Positive and negative TOEs have been reported even in time perception for which we do not have a dedicated sensory system. Allan (1979) discussed many studies on the TOE for temporal judgments, the discussion mainly revolving around the issue of whether the source of TOE is in the perceptual/memory stage or the decision/response stage.

A typical classic example of the perceptual-memory stance is Köhler's (1923) proposal for a physiological 
trace model to account for positive and negative TOEs. More recently, Schab and Crowder (1988), utilizing a technique developed in Crowder and Greene (1987) to disentangle perceptual and response factors, reported that the (negative) TOEs they found in a duration reproduction task were due to perceptual/memory factors. Also Hellström (1985), in his valuable review and modeling of the TOE, posits that the TOE should be classified as a perceptual phenomenon. This suggests at least one correspondence between TOE and TS: Both are certainly not the result of response bias but, rather, the cause of genuine perceptual/memory processes. Another correspondence is that in both the old TOE and the young TS tradition, the concept of assimilation plays an important role.

However, here the broad correspondence ends, and differences start to count: "The TOE effects are often (but not always) rather small, and they vary considerably from subject to subject" (Hellström, 1985, p. 36), whereas the underestimations owing to TS are enormous and the variability between participants is relatively low (e.g., ten Hoopen et al., 1993). Still another difference is that "as Postman pointed out, TOEs vary with the psychophysical method used" (Hellström, 1985, p. 36), whereas TS not only was established by the method of adjustment (e.g., Nakajima et al., 1992; Nakajima et al., 1991) but the illusory phenomenon also appeared clearly when we utilized the method of constant stimuli (e.g., ten Hoopen et al., 1993) and adaptive methods (e.g., Sasaki et al.,1998; ten Hoopen, Beumer, \& Nakajima,1996). Hellström (1985) also stated that the amount of training in TOE studies appears to interact intricately with such factors as stimulus magnitude and length of the interstimulus interval. Although we did not investigate the effect of training experimentally, in many of our studies we had several participants who were employed in consecutive experiments, and we are not yet aware of any decrease of their underestimations throughout the experiments.

One of the most crucial differences between TOE and TS assimilation is the restricted and precise time range of -15 to 95 msec differences between the durations of the second and the first intervals within which the TS mechanism operates. Still another difference is that TS diminishes considerably when the first interval duration exceeds 200 msec (e.g., ten Hoopen et al., 1993).

\section{Conclusion}

It is clear from the present study that the mechanism of TS also operates in sequences comprising three empty time intervals and that it operates not only between the last two time intervals, but also between the first two, and even between the first and the third one. It was evidenced that when the mechanism operated in the beginning of the sequence, its effect could propagate through the sequence, either abating or releasing the operation of the mechanism in the end of the sequence. It further turned out that the mechanism was susceptible to Gestalt principles in the temporal domain. In the cases of temporal proximity of the first two sound markers and of duration similarity of the first and the last intervals, the TS mechanism became inoperative.

It was shown that our perceptual system is very sensitive to the relationship between successive durations. An objective duration change of $P 1$ as small as $40 \mathrm{msec}$ can alter the perceived duration of $P 2$ and that of the last interval $S$ dramatically. An objective duration change of $P 2$ can change the perceived duration of the last interval $S$ likewise. It is our conjecture that the perceived temporal structure of the whole pattern can be altered conspicuously by minute changes of its individual components. ${ }^{1}$ But of course, our conjecture should be tested by experiments in which these temporal patterns have to be judged, compared, or discriminated as a whole, in the same vein as that in Handel (1998). More important, the outcomes of such experiments, combined with the present results, should be related to those models of rhythm perception in which the concepts of clocks, time, duration, and temporal patterning play crucial roles (e.g., Handel, 1992, 1993, 1998; Jones, 1990; Jones \& Boltz, 1989; Povel, 1981, 1984; Povel \& Essens, 1985).

\section{REFERENCES}

Allan, L. G. (1977). The time-order error in judgments of duration. Canadian Journal of Psychology, 31, 24-31.

Allan, L. G. (1979). The perception of time. Perception \& Psychophysics, 26, 340-354.

Allan, L. G., \& Gibbon, J. (1994). A new temporal illusion or the TOE once again? Perception \& Psychophysics, 55, 227-229.

Bregman, A. S. (1990). Auditory scene analysis. Cambridge, MA: MIT Press.

Crowder, R. G., \& Greene, R. L. (1987). On the remembrance of times past: The irregular list technique. Journal of Experimental Psychology: General, 116, 265-278.

FeChner, G. (1966). Elements of psychophysics (H. E. Adler, Trans.). New York: Holt. (Original work published 1860)

Fraisse, P. (1956). Psychologie du rythme [Psychology of rhythm]. Paris: Presses Universitaires de France.

HANDEL, S. (1989). Listening: An introduction to the perception of auditory events. Cambridge, MA: MIT Press.

HANDEL, S. (1992). The differentiation of rhythmic structure. Perception \& Psychophysics, 52, 497-507.

HANDEL, S. (1993). The effect of tempo and tone duration on rhythm discrimination. Perception \& Psychophysics, 54, 370-382.

HANDEL, S. (1998). The interplay between metric and figural rhythmic organization. Journal of Experimental Psychology: Human Perception \& Performance, 24, 1546-1561.

HellströM, A. (1985). The time order error and its relatives: Mirrors of cognitive processes in comparing. Psychological Bulletin, 97, 35-61.

JoNES, M. R. (1990). Musical events and models of musical time. In R.A. Block (Ed.), Cognitive models of psychological time (pp. 207240). Hillsdale, NJ: Erlbaum.

Jones, M. R., \& Boltz, M. (1989). Dynamic attending and responses to time. Psychological Review, 96, 459-491.

Jones, M. R, \& YeE, W. (1993). Attending to auditory events: The role of temporal organization. In S. McAdams \& E. Bigand (Eds.), Thinking in sound (pp. 69-112). Oxford: Oxford University Press, Clarendon Press.

KöHLER, W. (1923) Zur Analyse des Sukzessivvergleichs und der Zeitfehler [On the analysis of successive comparison and of the timeerror]. Psychologische Forschung, 4, 115-175.

LÜCK, H. E., \& Miller, R. (1993). Illustrierte Geschichte der Psychologie [Illustrated history of psychology]. Munich: Quintessenz. 
Metzger, W. (1953). Gesetze des Sehens [Laws of vision]. Frankfurt: Waldemar Kramer

Nakajima, Y., ten Hoopen, G., Hilkhuysen, G., \& Sasaki, T. (1992). Time-shrinking: A discontinuity in the perception of auditory temporal patterns. Perception \& Psychophysics, 51, 504-507.

Nakajima, Y., ten Hoopen, G., \& Van der Wilk, R. (1991). A new illusion of time perception. Music Perception, 8, 431-448.

Povel, D.-J. (1981). Internal representation of simple temporal patterns. Journal of Experimental Psychology: Human Perception \& Performance, 7, 3-18.

Povel, D.-J. (1984). A theoretical framework for rhythm perception. Psychological Research, 45, 315-337.

Povel, D.-J., \& Essens, P. J. (1985). The perception of temporal patterns. Music Perception, 2, 411-440.

Povel, D.-J., \& OKKerman, H. (1981). Accents in equitone sequences. Perception \& Psychophysics, 30, 565-572.

Remijn, G., van der Meulen, G., ten Hoopen, G., NaKajima, Y., KoMORI, Y., \& SASAKI, T. (1999). On the robustness of time-shrinking. Journal of the Acoustical Society of Japan, 20, 365-373.

Ross, J., \& Houtsma, A. J. M. (1994). Discrimination of auditory temporal patterns. Perception \& Psychophysics, 56, 19-26.

Sasaki, T., Nakajima, Y., \& TEN Hoopen, G. (1998). Categorical rhythm perception as a result of unilateral assimilation in time-shrinking. Music Perception, 16, 201-222.

SASAKI, T., Ten Hoopen, G., \& NAKaJIMa, Y. (1992). Time-shrinking in temporally separated conditions. In: C. Auxiette, C. Drake, \& C. Gérard (Eds.), Proceedings of the "Fourth Rhythm Workshop: Rhythm Perception and Production" (pp. 13-16). Bourges, France: Imprimerie Municipale.

Schab, F. R., \& Crowder, R. G. (1988). The role of succession in tem- poral cognition: Is the time-order error a recency effect of memory? Perception \& Psychophysics, 44, 233-242.

Suetomi, D., \& NaKaJima, Y. (1998). How stable is time-shrinking? Journal of Music Perception \& Cognition, 4, 19-25.

ten Hoopen, G., Beumer, M., \& NaKaJima, Y. (1996). What differs between the first and the last interval of a click sequence simulating a mora structure, the DT or the PSE? A replication of Tanaka, Tsuzaki, and Kato (1994). Journal of the Acoustical Society of Japan, 17, 155158.

ten Hoopen, G., Hartsuiker, R, Sasaki, T., Nakajima, Y., Tanaka, M., \& Tsumura, T. (1995). Auditory isochrony: Time-shrinking and temporal patterns. Perception, 24, 577-593.

ten Hoopen, G., Hilkhuy sen, G., Vis, G., Nakajima, Y., Yamauchi, F., \& SASAKI, T. (1993). A new illusion of time perception: II. Music Perception, 11,15-38.

Vos, P. G. M. M. (1973). Waarneming van metrische toonreeksen [Perception of metrical tone sequences]. Unpublished doctoral dissertation, University of Nijmegen.

Wert HeIMER, M. (1923). Untersuchungen zur Lehre von der Gestalt: II [Investigations for the science of Gestalts: II]. Psychologische Forschung, 4, 301-350.

\section{NOTE}

1. The reader can verify that by listening to demonstrations $25-27$ at http://www.kyushu-id.ac.jp/ ynhome/index.html.

(Manuscript received July 21, 1998;

revision accepted for publication November 28, 2001.) 